\title{
Are patients informed when they consent to ERCP?
}

\author{
Sinead O'Sullivan BKin, Craig Crippen MD, Terry Ponich MD FRCPC
}

\author{
S O'Sullivan, C Crippen, T Ponich. Are patients informed \\ when they consent to ERCP? Can J Gastroenterol \\ 2002;16(3):154-158.
}

BACKGROUND: Only the British Society of Gastroenterology has published consent guidelines that are inclusive for endoscopic retrograde cholangiopancreatography (ERCP). Previous research has shown that there are variations in the information discussed with patients who are undergoing ERCP.

PURPOSE: To examine the informed consent practices for ERCP in Ontario.

METHODS: A self-report questionnaire was sent to ERCP endoscopists in Ontario, who were identified through a pre-existing database. The 14-item questionnaire included questions pertaining to the risks, benefits and alternatives discussed, how consent was obtained and whether the consent process was modified for patients older than 75 years.

RESULTS: Of the 82 surveys sent, 36 responses were received, with three respondents indicating that they no longer performed ERCP; the total response rate was $40 \%$. Ninety-four per cent of those who responded noted that they obtained written consent, and $6 \%$ obtained verbal consent. When discussing risks with their patients, $91 \%$ of respondents always mentioned pancreatitis, $88 \%$ always mentioned bleeding, $73 \%$ always mentioned perforation and $30 \%$ always mentioned the risk of infection; only $24 \%$ always mentioned the possibility of being allergic to the contrast agent, and $73 \%$ rarely or never mentioned death. When dealing with patients older than 75 years, $38 \%$ of respondents tended to be more brief in their explanations, $31 \%$ gave the same details in their explanation and $31 \%$ gave more detailed information than they gave to younger patients. Seventy-nine per cent mentioned the possibility of diagnostic failure and $82 \%$ mentioned the possibility of therapeutic failure, while only $27 \%$ men- tioned the possibility of missing a diagnosis.

CONCLUSIONS: Variability exists in terms of 'important information' given to patients undergoing ERCP. Standard informed consent guidelines specific to ERCP may help endoscopists uphold their responsibility to the patient, enhance patient understanding and reduce the risk of liability.

Key Words: Endoscopic retrograde cholangiopancreatography; Informed consent; Litigation

\section{Cholangio-pancréatographie rétrograde endoscopique et consentement éclairé : qu'en est-il au juste?}

CONTEXTE : Seule la British Society of Gastroenterology a publié des lignes de conduite relatives au consentement éclairé, applicables à la cholangio-pancréatographie rétrograde endoscopique (CPRE). Des recherches antérieures ont montré qu'il existe des écarts quant à l'information livrée aux patients devant subir une CPRE.

OBJECTIF : Examiner les pratiques relatives au consentement éclairé en Ontario en ce qui concerne les CPRE.

MÉTHODE : Un questionnaire d'auto-déclaration a été envoyé à des endoscopistes pratiquant des CPRE en Ontario; le choix s'est fait à partir d'une base de données préexistante. Le questionnaire en 14 points portait sur les avantages et les risques de l'intervention ainsi que les solutions de rechange, le type de consentement obtenu et les modifications possibles du processus de consentement pour les patients de plus de 75 ans.

RÉSULTATS : Nous avons reçu 36 réponses sur une possibilité de 82, et trois répondants ont fait savoir qu'ils ne pratiquaient plus de CPRE, ce qui

suite à la page suivante 
porte à $42 \%$ le taux de réponse total. Quatre-vingt-quatorze pour cent des répondants ont indiqué qu'ils avaient obtenu un consentement écrit, et $6 \%$, un consentement oral. Quant aux risques discutés avec les patients, $91 \%$ des médecins ont noté qu'ils mentionnaient toujours la possibilité de pancréatite; $88 \%$, la possibilité d'hémorragie; $73 \%$, la possibilité de perforation; $30 \%$, la possibilité d'infection et $24 \%$ seulement, la possibilité de réaction allergique au produit de contraste. Soixante-treize pour cent n'ont jamais ou rarement mentionné la possibilité de mort. Quant au traitement réservé aux patients de plus 75 ans, $38 \%$ des répondants avaient tendance à donner moins d'information; 31 \%, à en donner autant et $31 \%$, à en donner plus qu'aux autres. Soixante-dix-neuf pour cent des médecins ont indiqué la possibilité d'échec du diagnostic; $82 \%$, la possibilité d'échec du traitement et $27 \%$ seulement, la possibilité de manguer quel que chose.

CONCLUSION : Il existe des écarts quant à l'importance de l'information livrée aux patients devant subir une CPRE. L'élaboration de lignes de conduite uniformisées, relatives au consentement éclairé et propres à la CPRE pourrait aider les endoscopistes à confirmer leur responsabilité à l'égard du patient, à améliorer la compréhension de l'intervention par ce dernier et à diminuer les risques de poursuite.
$\mathrm{P}$ hysicians in the specialty of gastroenterology encounter the issue of informed consent more often than those in most other medical specialties, making it especially important for gastroenterologists to obtain adequate informed consent (1). Previous research has shown that, in general, endoscopists fail in their duty to provide adequate information to their patients (2). Other reports have indicated that endoscopists obtain consent for endoscopy procedures, including endoscopic retrograde cholangiopancreatography (ERCP), in a variant fashion $(1,3)$. Patients have a right to be properly informed before a medical investigation. Failure to do so leaves gastroenterologists open to litigation (4-6).

Because courts have been holding physicians liable on the basis of failure to obtain adequate informed consent, in conjunction with courts' heavy reliance on progress notes, documenting consent is often more important to the gastroenterologist than engaging in the actual informed consent process itself (1). Obtaining informed consent has become an administrative step in the process of seeing patients rather than a discussion of the procedures, risks, benefits and fears of the patient to lead him or her to an informed decision (7). The majority of patients undergoing medical therapy do not properly read consent forms (1). Patients are more interested in what physicians say rather than what they have read or signed. However, written information is also important because it can be easily administered and updated by other health care providers, and provides permanent documentation of information provided to the patient. The primary goal of obtaining informed consent is that the patient has the opportunity to be an informed participant in the making of his or her health care decisions.

ERCP is a complex procedure with a relatively high complication rate. Diagnostic ERCP carries a complication rate of approximately 3\% (8). Therapeutic ERCP with sphincterotomy is associated with more risk and has a complication rate of approximately $9 \%(8,9)$. Complications of ERCP are well recognized and include pancreatitis $(5.4 \%)$ and bleeding $(2.0 \%)$, and a death rate of up to $0.4 \%(3,8,9)$. According to the law, risk with severe consequences, even if miniscule, is considered a material risk and must be disclosed $(2,7)$. Death, for example, is a severe consequence and must be disclosed, even if the chance of it occurring is low. Physicians have been found to disclose only risks with a high probability of occurrence and to provide little infor- mation regarding alternative therapies or interventions $(3,10)$.

Patients undergoing ERCP are often older than 75 years and present a high level of morbidity. Previous research has shown that healthy patients retain more information about risks and side effects than severely ill patients (10). Consent documents have also been shown to be less useful for patients with severe disease (10). Gostout (11) recommended that ERCP endoscopists present important information to severely ill or elderly patients more than once so that the patient understands the risk to benefit ratio associated with ERCP. Elderly patients have additional needs that must be addressed in a situation of gastrointestinal illness, ie, risks, avoidance of costly interventions and surrogate decision-makers (11).

Patients who have not been adequately informed and subsequently experience negative ramifications as a result of a procedure are more likely to sue (5). In the United States, $1 \%$ of medical liability claims have been related to endoscopic procedures (4). Of 85 malpractice claims against gastroenterologists that have been analyzed, 37 arose from adverse events that occurred during endoscopy, 13 of which were ERCPs. In 31 of these endoscopy cases, there appeared to be significant fault on the part of the physician (12). Most ERCP lawsuits centre on the occurrence of severe complications (3). Neale (12) maintained that there would have been few claims if proper informed consent had been obtained. The British Society of Gastroenterology is the only association with published informed consent guidelines inclusive of ERCP (4).

The purpose of the present study was to build on the limited literature related to informed consent practices for ERCP by examining the current standards of obtaining informed consent before ERCP in Ontario.

\section{METHODS}

A self-report questionnaire was sent to ERCP endoscopists practising in Ontario (Appendix 1). These physicians were identified through a pre-existing database. Physicians in the database included all ERCP endoscopists practising at an Ontario hospital with 100 or more beds. The survey was sent out only once and comprised 14 items pertaining to the risks, benefits and alternatives discussed; how consent was obtained; and whether the consent process was modified for patients older than 75 years. 
TABLE 1

Documentation of disclosure of information in patients' charts before endoscopic retrograde cholangiopancreatography (ERCP)

\begin{tabular}{lccc}
\hline Type of information & $\begin{array}{c}\text { Always } \\
(\%)\end{array}$ & $\begin{array}{c}\text { Sometimes } \\
(\%)\end{array}$ & $\begin{array}{c}\text { Never } \\
(\%)\end{array}$ \\
\hline Procedural information & 48 & 42 & 9 \\
Risks & 42 & 51 & 6 \\
Benefits & 39 & 51 & 9 \\
Alternatives to ERCP & 24 & 57 & 18 \\
\hline
\end{tabular}

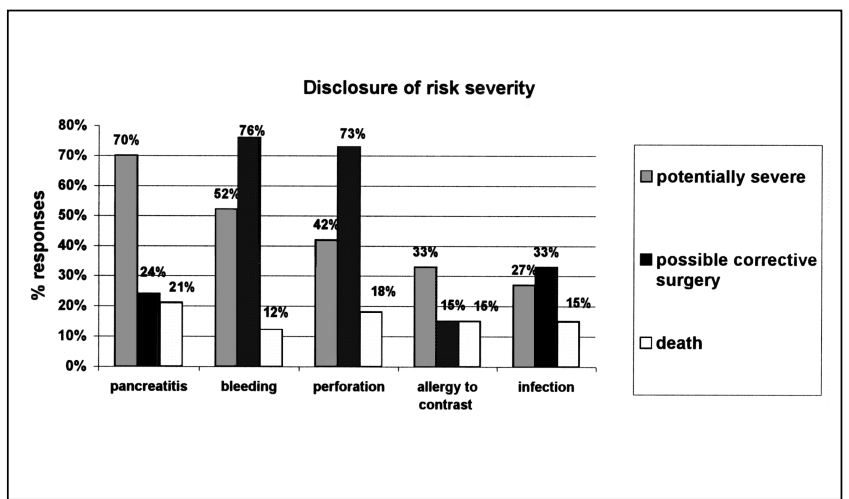

Figure 1) Respondents' disclosure of risk severity for the various potential consequences of endoscopic retrograde cholangiopancreatography

\section{Design and statistical considerations}

This was a cross-sectional, questionnaire-based, descriptive study. Results are expressed as a percentage of responses received per question.

\section{RESULTS}

Of the 82 surveys sent, 36 responses were received, with three respondents indicating that they no longer performed ERCP. Therefore, the total response rate was $40 \%(n=33)$.

The mean number of years in practice for respondents was 13.58 (SD 4.97), and the mean number of ERCPs performed per year was 160.25 (SD 166.32). Eighty-eight per cent of the respondents were gastroenterologists, $9 \%$ were general surgeons and $3 \%$ were radiologists. Seventy per cent of respondents practised in an academic centre and 30\% practised in the community.

One hundred per cent of the respondents indicated that they disclosed all procedural information, including risks, benefits and alternatives, to their patients. Table 1 and Figure 1 outline the risks and severity of risks discussed with patients undergoing ERCP. Nine per cent of respondents never mentioned the risk of perforation, which is a risk encountered during all endoscopic procedures. Sixty-seven per cent of respondents never mentioned the risk of death,

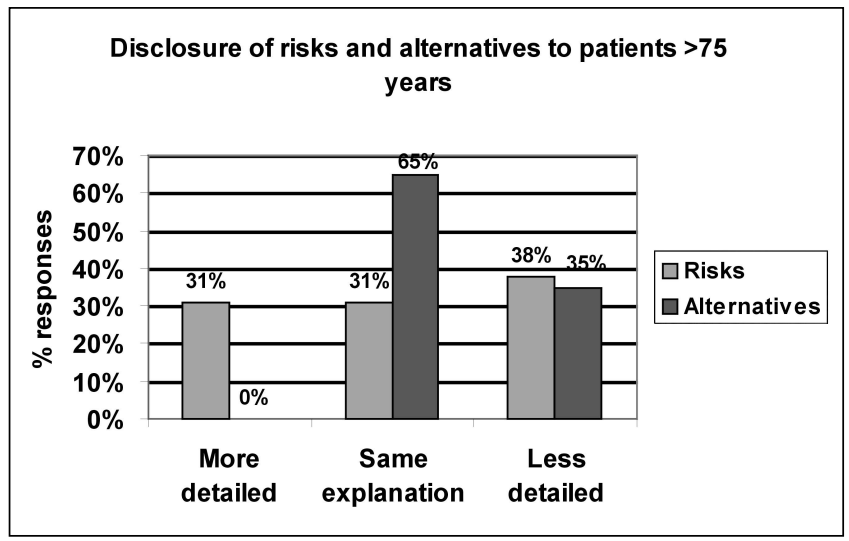

Figure 2) Respondents' levels of explanation of details (risks and alternatives) to patients older than 75 years. Almost $40 \%$ of respondents provided these patients with a less detailed explanation of the risks involved in endoscopic retrograde cholangiopancreatography than they gave to younger patients

and only $59 \%$ of respondents considered death to be a material risk. Figure 2 outlines how respondents modified their informed consent practices for patients older than 75 years. As far as other procedural complications of ERCP were concerned, $21 \%$ of respondents did not disclose the chance of diagnostic failure, $18 \%$ of respondents did not disclose the chance of therapeutic failure and $73 \%$ of respondents did not tell their patients of the chance that ERCP may miss a diagnosis.

Consent was most commonly obtained in written form $(94 \%)$, with only $6 \%$ of respondents relying on verbal consent. Less than $50 \%$ of respondents documented informed consent information in their patients' charts. How thoroughly alternatives to ERCP were offered was not documented; Table 1 shows that the alternatives discussed are not documented regularly.

\section{DISCUSSION}

ERCP endoscopists perform a procedure with a relatively high complication rate involving patients who are often elderly and/or severely ill. Procedures with severe complications increase the likelihood of litigation. We speculate that the low response rate to our questionnaire may be an indication of physicians' discomfort with this topic. Therefore, ERCP endoscopists must implement thorough informed consent practices to ensure that the patient understands his or her health status and the best individual health management options.

It is generally accepted that obtaining informed consent includes the following elements: disclosure of the nature of the procedure, reasonable alternatives to the proposed intervention, risks and possible complications of the procedure, benefits of the procedure and an assessment of the patient's understanding $(2,7,13)$. This does not appear to be the current routine standard of practice in Ontario. We found that, in Ontario, the practice for obtaining informed consent for ERCP is quite variable, possibly due to the lack 
of practice guidelines specific to ERCP in Canada or the United States. Some informed consent guidelines suggest employing the 'reasonable physician standard', which allows the physician to determine what information should be discussed with the patient (13). Previous research has shown that this standard does not provide the patient with enough desired information (13). Instead, especially for complex procedures such as ERCP, the 'reasonable patient standard' should be employed, which focuses on what information an average patient needs to know to make an informed decision (13). Understanding the patient's needs and perceptions will help endoscopists to inform them better (1).

One important finding of the present study was that only $18 \%$ of physicians always mentioned the chance of death to patients undergoing ERCP and $67 \%$ of respondents never mentioned it. It is understood among physicians that ERCP is usually the best of the available options for most patients. Percutaneous and operative common bile duct exploration have higher morbidity and mortality rates, while endoscopic ultrasound and magnetic resonance cholangiopancreatography are not yet widely available in Canada. There are additional reasons why physicians may not explain all other options to their patients, including the lack of time to teach patients of the details and circumstances of each choice, and the potential for confusing patients and leading them to making a more dangerous choice. Nonetheless, under Canadian law, any 'material risk' must be disclosed (7), including the $0.4 \%$ chance of death directly related to ERCP (9). The primary reason (84\% of physicians) for not mentioning death was that there is "a low chance of it occurring". We found variability between which risks were discussed and the severity of each risk. For example, $91 \%$ of respondents always mentioned the risk of pancreatitis associated with ERCP, $73 \%$ always mentioned the risk of perforation and $25 \%$ always mentioned the risk of an allergic reaction to the contrast agent. We recommend that the risk of pancreatitis, bleeding, perforation and death should always be discussed with every patient who is to undergo ERCP.

Finally, we found that less than $50 \%$ of physicians documented consent information in a patient's chart. A brief, routine mention of the informed consent discussion and patient comprehension during dictation may remind physicians to discuss more completely the procedure and reduce their possible legal risk. If physicians choose not to review the risks with their patients because, in their opinion, it is not in the patient's best interest, then this decision should be documented to avoid the appearance of negligence.

In addition to the issue of what information should be disclosed, the question of when the information should be disclosed has also been a topic of interest in the literature. We did not examine this issue in our study; however, it has been agreed that requesting consent hastily only moments before a procedure is unsatisfactory (14). It has been suggested in the literature that patients should receive information regarding the procedure in the mail before the date of the procedure and that consent should be obtained at least 30 min before the investigation (14). One study examined the effectiveness of a specifically designed information booklet with an integral consent form that was mailed to patients before their procedure; the booklet was accepted by patients and improved their understanding of the procedure that they were to undergo - upper intestinal endoscopy (15). Given the complex nature of ERCP compared with other upper endoscopy procedures, an information booklet for ERCP may be an effective informed consent tool. An information booklet would allow a patient to take his or her time to understand the procedure and eliminates the power imbalance between patient and gastroenterologist that exists outside the comfort of the patient's home (15).

The British Society of Gastroenterology has published guidelines specific to ERCP indicating that the patient should be provided with written information about acute pancreatitis, cholangitis, perforation and bleeding (4). ERCP involving the insertion of a stent carries additional considerations that must be addressed because of the potential short term and long term consequences (4). In an audit of 16 of 18 endoscopy units in the northern region of the United Kingdom, it was found that adequate informed consent was provided in only four instances (4). Our results are similar, indicating that ERCP endoscopists not only fail to provide written information about these complications, but in some cases do not disclose the risks at all (Figure 1).

Our findings are generally consistent with those of a study conducted in Indiana in 1994, which also looked at informed consent practices via questionnaire (3). One consideration that was not addressed by Newton et al (3) was the issue of information disclosed to patients older than 75 years. While elderly patients, who are often very ill, require special care and attention regarding the informed consent process, we found that a high proportion of respondents are more inclined to be less detailed in their explanations with this population than with younger patients (Figure 2). It is important that ERCP endoscopists are sensitive to the added planning and decision making required for the health care management of elderly patients (11). As providers of health care, gastroenterologists need to be aware of and be involved in outcomes and quality assessment of their practice (16).

\section{CONCLUSIONS}

It is evident that a high degree of variability exists in the information that is disclosed to patients undergoing ERCP. Our results indicate that, in Ontario, many patients do not receive a complete description of the benefits and complications of, and alternatives to, ERCP. There are no practice guidelines specific to ERCP in the United States or Canada. Standard practice guidelines may reduce the variability of, and therefore improve, the informed consent practice. We advocate the development of American and Canadian informed consent guidelines specific to ERCP, which may help endoscopists enhance patients' understanding of the procedure and reduce their own risk of liability. 


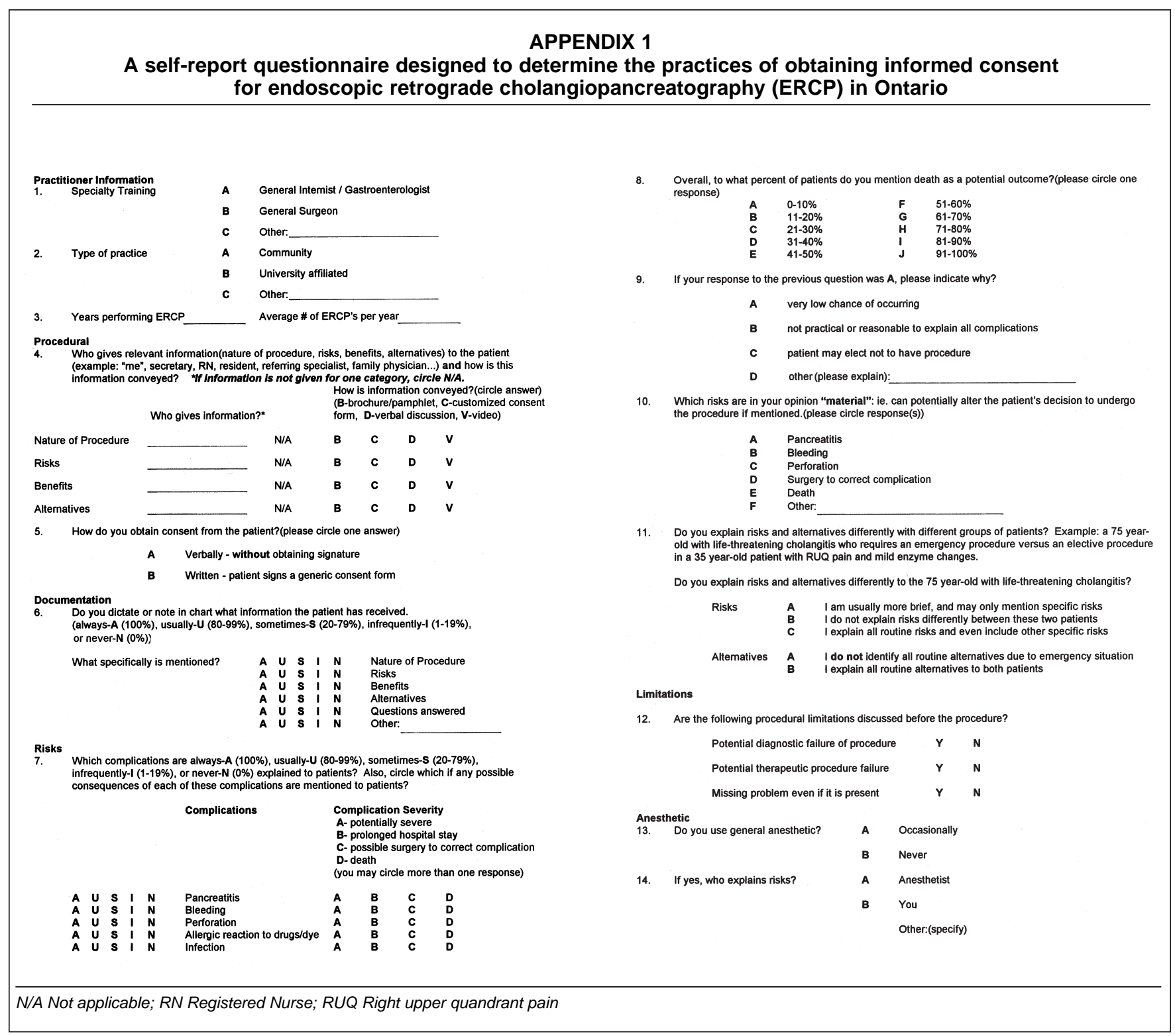

\section{REFERENCES}

1. Kirsch M. The myth of informed consent. Am J Gastroenterol 2000;95:588-9.

2. Informed Consent: Guidelines for Gastrointestinal Endoscopy. Mississauga: Canadian Association of Gastroenterology, May 1997.

3. Newton J, Hawes R, Jamidar P, et al. Survey of informed consent for endoscopic retrograde cholangiopancreatography. Dig Dis Sci 1994;39:1714-8

4. Guidelines for Informed Consent for Endoscopic Procedures. London: British Society of Gastroenterology, January 1999.

5. Neale G. Informed consent. Gut 2000;46:5-6.

6. Sato RL, Yamamoto LG, Li GG. Malpractice risk assessment among different approaches for informed consent. Hawaii Med J 2000;59:357-61.

7. The Canadian Medical Protective Association. Consent: A Guide for Canadian Physicians, 3rd edn. Ottawa: The Canadian Medical Protective Association, 1996:11-14.

8. ASGE guidelines for clinical application. The role of ERCP in disease of the bilary tract and pancreas. American Society for

Gastrointestinal Endoscopy. Gastrointest Endosc 1999;50:915-20.

9. Freeman ML, Nelson DB, Sherman S, et al. Complications of endoscopic biliary sphincterotomy. N Engl J Med 1996;335:909-18.

10. Schaeffer MH, Krantz DS, Wichman A, Masur H, Reed E, Vinicky JK. The impact of disease severity on the informed consent process in clinical research. Am J Med 1996;100:261-8.

11. Gostout CJ. Gastrointestinal bleeding in the elderly patient. Am J Gastroenterol 2000;95:590-5.

12. Neale G. Reducing risks in gastroenterological practice. Gut 1998;42:139-42.

13. University of Washington School of Medicine. Ethics in Medicine: Informed Consent (February 22, 1999).

$<$ http://eduserv.hscer.washington.edu/bioethics/topics/consent.html> (Version current at November 20, 2000)

14. Quine MA, Colin-Jones D. Safe practice of endoscopy. Postgrad Med J 2000;76:455-6.

15. Shepherd HA, Bowman D, Hancock B, et al. Postal consent for upper gastrointestinal endoscopy. Gut 2000;46:37-9.

16. Quality and outcomes assessment in gastrointestinal endoscopy. American Society for Gastrointestinal Endoscopy. Gastrointest Endosc 2000;52:827-30. 


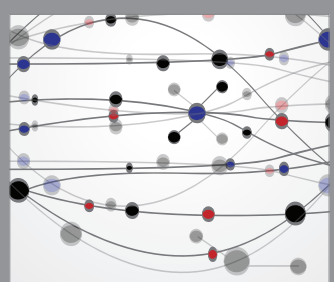

The Scientific World Journal
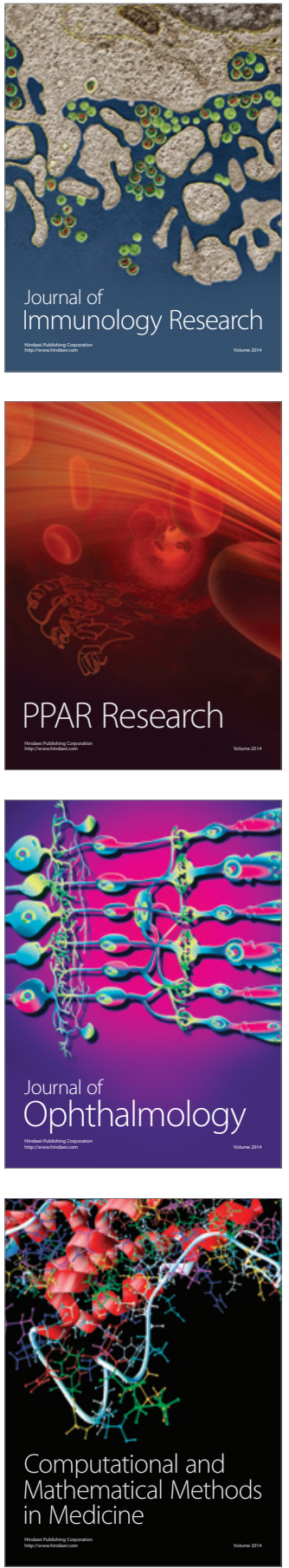

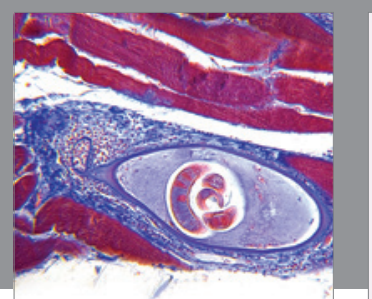

Gastroenterology Research and Practice

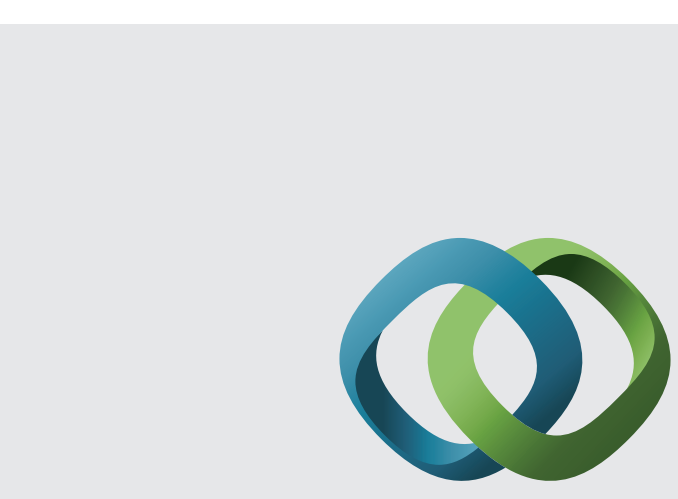

\section{Hindawi}

Submit your manuscripts at

http://www.hindawi.com
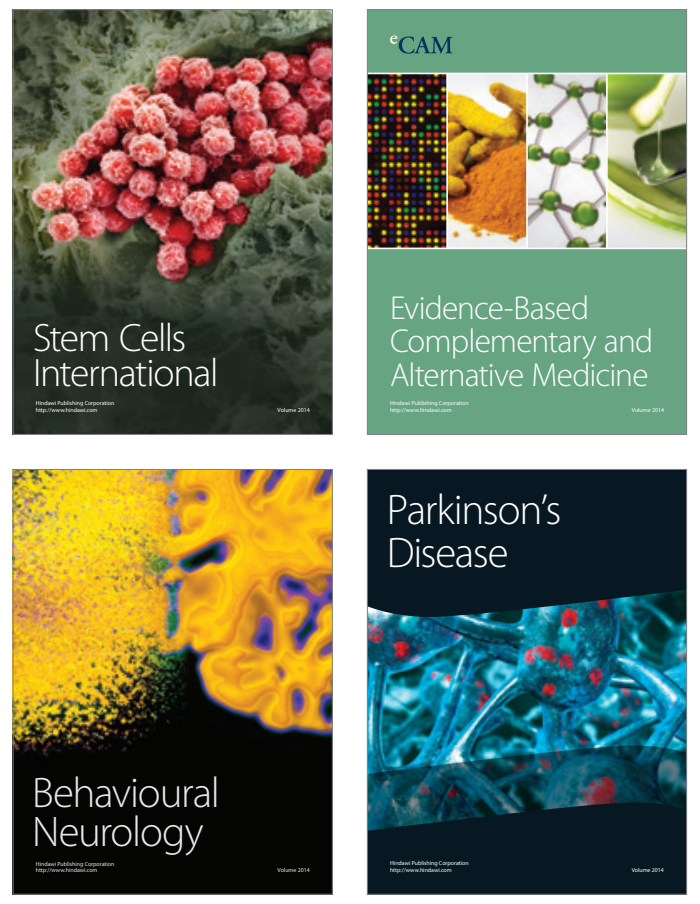
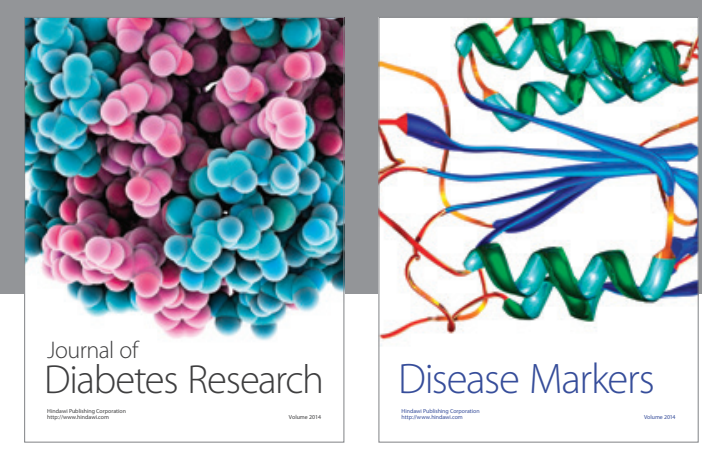

Disease Markers
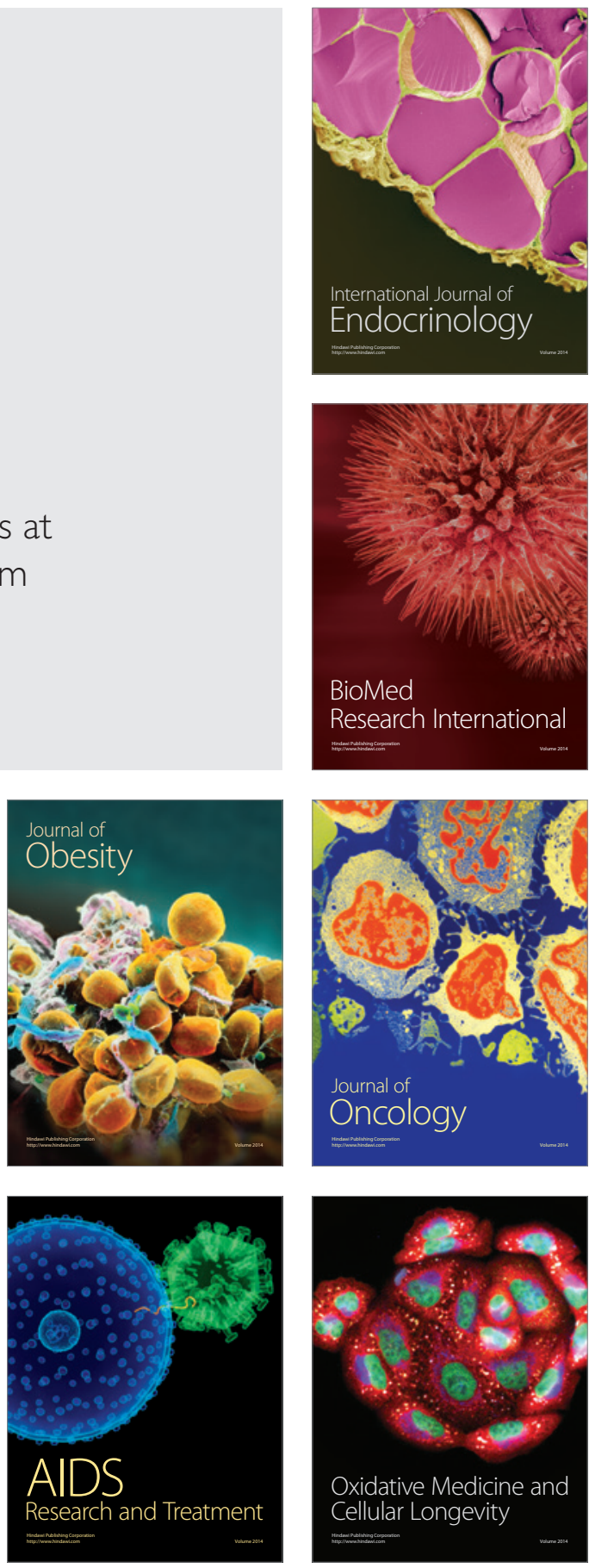